\title{
Expression of Cancer/Testis Antigens is Correlated with Improved Survival in Glioblastoma
}

\author{
Marcelo Roberto Pereira Freitas ${ }^{1}$, Suzana Maria Fleury Malheiros², João Norberto \\ Stávale $^{3}$, Thais Priscila Biassi ${ }^{1}$, Fernando Tadeu Zamunér ${ }^{1}$, Maria Dirlei Ferreira \\ de Souza Begnami ${ }^{4}$, Fernando Augusto Soares ${ }^{4}$, Andre Luíz Vettore ${ }^{1}$ \\ ${ }^{1}$ Cancer Molecular Biology Laboratory, Department of Science Biology, Federal University of São Paulo, Rua Pedro de Toledo, \\ São Paulo, SP, Brazil \\ 2 Department of Neurology, Federal University of São Paulo, Rua Botucatú,São Paulo, SP - Brazil \\ ${ }^{3}$ Department of Pathology, Federal University of São Paulo, Rua Botucatú, São Paulo, SP - Brazil \\ ${ }^{4}$ Department of Pathology, A C Camargo Cancer Hospital, Rua Prof. Antônio Prudente, São Paulo, SP, Brazil. \\ Correspondence to: André L. Vettore, email: andre.vettore@gmail.com
}

Keywords: Brain cancer, Glioblastoma, GBM, Cancer/Testis antigens, CTA expression

Received: March 27, $2013 \quad$ Accepted: April 13, $2013 \quad$ Published: April 15, 2013

This is an open-access article distributed under the terms of the Creative Commons Attribution License, which permits unrestricted use, distribution, and reproduction in any medium, provided the original author and source are credited.

\section{ABSTRACT:}

Background: Glioblastoma (GBM) confers a dismal prognosis despite advances in current therapy. Cancer-testis antigens (CTA) comprise families of tumor-associated antigens that are immunogenic in different cancers. The aim of this study was to determine the expression profile of a large number of CTA genes in GBM.

Methods: We selected, from 153 CTA genes, those genes potentially expressed in GBM. The expression pattern of 30 CTA was then evaluated by RT-PCR in a series of $48 \mathrm{GBM}$ and 5 normal brain samples. The presence of CTCFL protein was also evaluated by immunohistochemical staining.

Results: Among the genes with no expression in normal brain, ACTL8 (57\%), OIP5 (54\%), XAGE3 (44\%) and CTCFL (15\%) were frequently expressed in GBM, while over $85 \%$ of the tumors expressed at least 1 of these four CTA. Coexpression of two or more CTA occurred in $49 \%$ of cases. CTCFL protein expression was detected in $13 \%$ of the GBM and was negative in normal brain samples. GBM expressing 3-4 CTA was associated with significantly better overall survival $(O S)$ rates $(P=0.017)$. By multivariate analysis, mRNA positivity for 3-4 CTA $(P=0.044)$, radiotherapy $(P=$ $0.010)$ and chemotherapy $(P=0.001)$ were independent prognostic factors for $O S$.

Conclusions: GBM frequently express ACTL8, OIP5, XAGE3 and CTCFL. A relatively high percentage of tumors expressed at least one of these four CTA, opening the perspective for their utility in antigen-specific immunotherapy. Furthermore, mRNA positivity for 3-4 CTA is an independent predictor of better OS for GBM patients.

\section{INTRODUCTION}

Glioblastoma is the most common primary malignant brain tumor in adults. The current treatment of GBM, which consists of surgical resection followed by radiation therapy and chemotherapy, has a median survival of 14.6 months (1). Moreover, conventional therapy is often associated with considerable local and systemic side effects. Therefore, the development of novel therapeutic approaches is essential to improve the outcome of GBM patients $(2,3)$.

The discovery of tumor antigens has opened new doors for specific tumor-targeted treatments using passive or active immunotherapeutic strategies. One group of these antigens, the so-called cancer/testis antigens, is present in germ cells in a variety of cancers yet rarely found in normal adult tissues (4-6). The present catalog of CTA comprises more than 200 distinct genes (7). As spontaneous anti-tumor immune responses can be elicited by CTA, they represent promising candidates for cancer immunotherapy. In recent years, several CTA, particularly 
MAGE-A3 and NY-ESO-1, have been studied as target antigens in vaccine clinical trials for many cancer types (8), including GBM (9).

The expression frequencies of some CTA in GBM have been determined but little is known about their composite expression (10-15). This information is crucial in designing immunotherapeutic strategies, because it is mandatory to know what proportion of patients can be expected to be eligible and which antigens have to be chosen (16). To better understand the expression profile of CT antigens in GBM, we conducted an extensive expression analysis of these genes in glioblastoma and normal brain specimens from adult patients.

\section{RESULTS}

\section{Patient baseline characteristics}

Forty-eight patients with histologically diagnosed glioblastoma (WHO Grade IV), that had fresh frozen samples available, were enrolled in this study (Supplementary Table S2). One patient was treated in another hospital and was lost to follow-up. The sample comprised $14(29 \%)$ women and 34 (71\%) men, with a median age of $54( \pm 14)$ years. Twenty-one patients $(45 \%)$ had a Karnofsky performance status (KPS) $>70$. All patients underwent biopsy (23\%) or resection of the tumor (44\% subtotal and 33\% gross total resection), and $64 \%$ of patients received standard, external beam radiation therapy. At least $43 \%$ of patients received adjuvant chemotherapy.

\section{Selection of CTA genes}

Candidate CTA genes with a high probability of being expressed in GBM were selected by in silico screening using all 153 CTA genes previously described by Hofmann et al (5). First of all, 14 CTA genes classified as testis/brain restricted by Hofmann et al were excluded. The remaining 139 CTA genes were used to search the NCBI-CGAP SAGE database, Oncomine and NExtBio collections of microarray data, published data of CTA mRNA expression (CTDatabase) and high-throughput expression data also provided by Hofmann et al. Ultimately, a total of 30 CTA were selected (ACTL8, BAGE, BRDT, CSAG2, CTAG1A, CT45, CTCFL, CXORF48, CXORF61, DDX53, FTHL17, MAGEA1, MAGEA2, MAGEB4, MAGEB6, NFX2, OIP5, PBK, ROPN1, SCLO6A1, SPANXN1, SPANXN2, SPANXN3, SPANXN4, SPINLW1, SPO11, SSX7, XAGE1, XAGE3 and $Z N F 165$ ) for assessment of gene expression in a context of potential high expression in GBM samples and absence in normal brain.

\section{Analysis of CTA genes expression in GBM}

Based on the above results, 30 CTA genes were selected for evaluation in GBM and normal adult tissue samples using RT-PCR analysis. Representative examples of RT-PCR results are shown in Supplementary Figure 1.

Due to the limited quantity of RNA of many samples and the number of genes selected, it would have been virtually impossible to evaluate all possible candidate-

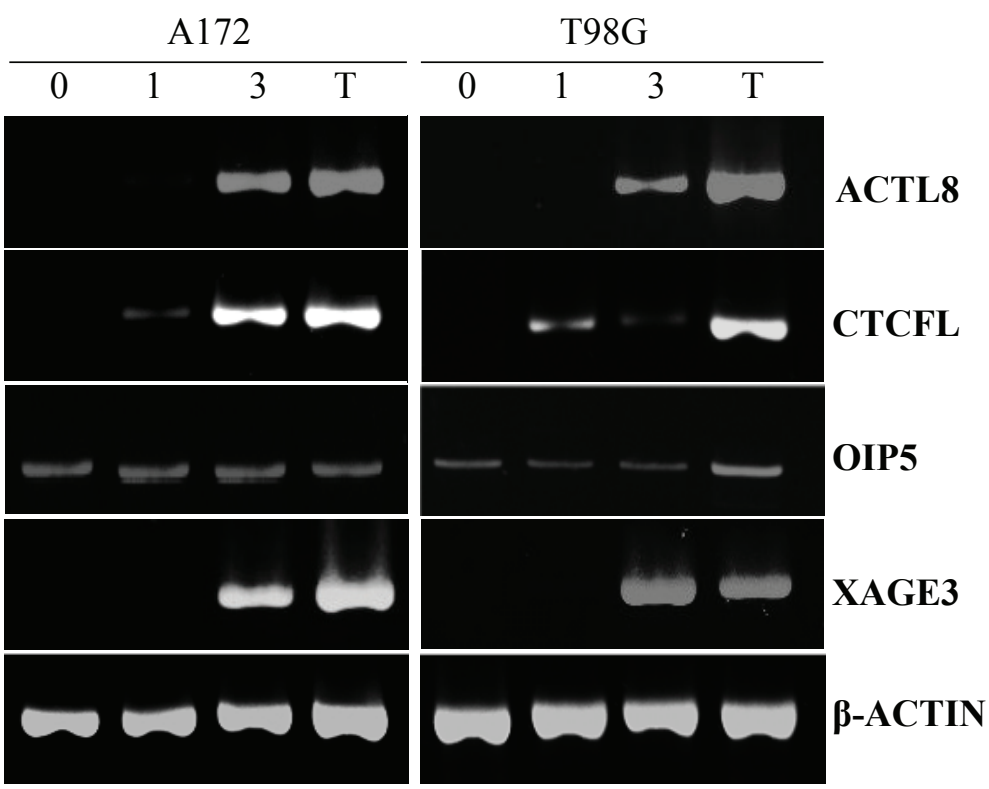

Figure 1: RT-PCR for $A C T L 8, C T C F L, O I P 5$ and $X A G E 3$ expression in GBM cell lines treated with decitabine (DAC). A172 and T98G cell lines were treated with 5mM DAC for 3 days. (0) untreated; (1) one-day DAC treatment; (3) three-day DAC treatment; (T) testis tissue was used as a positive control. Amplification of $\beta$-ACTIN is shown as reference. Only OIP5 was expressed in these cell lines before DAC treatment. 


\begin{tabular}{|c|c|c|c|}
\hline & \begin{tabular}{|l|l|}
$\begin{array}{l}\text { GBM } \\
\text { samples }\end{array}$ \\
\end{tabular} & & \begin{tabular}{|l|} 
Normal \\
Brain (5) \\
\end{tabular} \\
\hline \multirow[t]{3}{*}{ CT Genes } & & & $\%(n)$ \\
\hline & \begin{tabular}{|l} 
Discovering \\
Set (17)
\end{tabular} & \begin{tabular}{|l|} 
Validation \\
Set $(48)$
\end{tabular} & \\
\hline & $\%(n)$ & $\%(n)$ & \\
\hline BRDT & $0(0)$ & - & _. \\
\hline CSAG2 & $0(0)$ & - & - \\
\hline CTAG1A & $0(0)$ & - & - \\
\hline CT45 & $0(0)$ & - & - \\
\hline CXORF61 & $0(0)$ & - & - \\
\hline MAGEA2 & $0(0)$ & - & - \\
\hline MAGEB4 & $0(0)$ & - & - \\
\hline SLCO6A1 & $0(0)$ & - & - \\
\hline SPANX N1 & $0(0)$ & - & - \\
\hline SPANX N2 & $0(0)$ & - & - \\
\hline SPANX N3 & $0(0)$ & - & - \\
\hline SPANX N4 & $0(0)$ & - & - \\
\hline SSX7 & $0(0)$ & - & - \\
\hline MAGEA1 & $6(1)$ & - & - \\
\hline MAGEB6 & $6(1)$ & - & - \\
\hline BAGE & $12(2)$ & - & - \\
\hline SPO11 & $12(2)$ & - & - \\
\hline NFX2 & $18(3)$ & - & - \\
\hline \begin{tabular}{|l|} 
XAGE1 \\
\end{tabular} & $18(3)$ & - & - \\
\hline CXORF48 & $35(6)$ & - & $100(5)$ \\
\hline SPINLW1 & $46(8)$ & - & $60(3)$ \\
\hline FTHL17 & $76(13)$ & - & $80(4)$ \\
\hline ROPN1 & $82(14)$ & - & $100(5)$ \\
\hline DDX53 & $94(16)$ & - & $100(5)$ \\
\hline ZNF165 & $100(17)$ & - & $100(5)$ \\
\hline PBK & $100(17)$ & - & $100(5)$ \\
\hline CTCFL* & $24(4)$ & $15(7)$ & $0(0)$ \\
\hline OIP5 & $29(5)$ & $54(26)$ & $0(0)$ \\
\hline ACTL8* & $46(8)$ & $57(21)$ & $0(0)$ \\
\hline XAGE3 & $94(16)$ & $48(23)$ & $0(0)$ \\
\hline
\end{tabular}

${ }^{*}$ CTCFL and ACTL8 were analyzed in 46 and 37 GBM samples, respectively.

genes in all samples. Consequently, it was decided to first conduct a discovery study to yield a more limited set of "best" CTA genes for use in the validation set. The first step was to verify the expression status of 30 CTA genes in 17 GBM samples. According to this analysis, no expression of BRDT, CSAG2, CTAG1A, CT45, CXORF61, MAGEA2, MAGEB4, SLCO6A1, SPANX N1, SPANX N2, SPANX N3, SPANX N4 or SSX7 was detected in the GBM samples examined, whereas $M A G E-A 1(6 \%), M A G E-B 6$ (6\%), BAGE (12\%), SPO11 (12\%) NFX2 (18\%), and $X A G E 1$ (18\%) transcripts were rarely detected. On the other hand, 11 CTA genes, CXORF48 (35\%), ROPN1 (82\%), DDX53 (94\%), ZNF165 (100\%), PBK (100\%), FTHL 17 (76\%), SPINLW1 (46\%), CTCFL (25\%), XAGE3 (94\%), OIP5 (29\%) and ACTL8 (46\%) were frequently expressed in GBM cases (Table 1).

In the next step, the expression pattern of these 11 CTA genes in five normal brain specimens was evaluated using the same conditions defined for the tumor samples. This analysis showed that only ACTL8, CTCFL, OIP5 and $X A G E 3$ were not expressed in normal brain. Hence, expression of these four antigens was evaluated in the validation set revealing that $A C T L 8$ had the highest incidence of mRNA positivity ( $57 \%$ ), followed by OIP5 (54\%), XAGE3 (48\%) and CTCFL (15\%) (Table 1). Notably, $86 \%$ of the GBM cases showed expression of at least one CTA gene from the panel selected. Among them, $39 \%$ of the cases expressed only one of these CTA genes. Coexpression of two, three and four CTA genes occurred in $25 \%, 17 \%$ and $5 \%$ of the examined GBM cases, respectively.

The expression of these four CTAs was also examined in two GBM cell lines (A172 and T98G) and only OIP5 transcripts were detected in these cell lines (Figure 1).

\section{Expression of CTCFL, XAGE3, OIP5 and ACTL8 in Human Normal Tissues}

The expression of the four selected CTA genes was investigated by RT-PCR in a panel of 16 distinct normal tissues. As can be seen from Figure 2, all four CTA genes under investigation were not expressed in normal brain, but presented low expression at different frequencies in other normal adult tissues. ACTL8 was expressed in normal colon, skeletal muscle, bladder, adrenal gland, thymus, uterus and pancreas, whereas $C T C F L$ expression was detected only in spleen. OIP5 was expressed in thymus, adrenal gland and small intestine while $X A G E 3$ transcripts were present in skeletal muscle, bladder, lung, thymus, uterus and breast. The expression of these CTA genes was not detectable in other normal tissues evaluated.

\section{Immunohistochemical analysis of CTCFL protein}

The RT-PCR technique is a sensitive method for the detection of CTA messenger RNA synthesis, but in order to verify that CTA genes are also expressed at the protein level, sectioned materials from formalinfixed GBM (92), anaplastic astrocytomas (15), grade II 
astrocytomas (48) and grade I astrocytomas (38) were analyzed by IHC. Protein expression of CTCFL was the only analysis performed because antibodies against XAGE3, OIP5 and ACTL8 for immunohistochemical assays were unavailable. Diffuse cytoplasmic staining for CTCFL was present in 13\% (12/92) of GBM cases (Figure 3). Immunoreaction to $C T C F L$ was negative in all anaplastic astrocytomas $(0 / 15)$, diffuse astrocytomas $(0 / 48)$, pilocytic astrocytomas $(0 / 38)$ and normal brain samples $(0 / 40)$ examined.

\section{Up-regulation of CTA expression on GBM cells by DAC treatment}

To determine whether the treatment of GBM cell lines with DAC would alter the expression of $A C T L 8$, $C T C F L, O I P 5$ and $X A G E 3$, two GBM cell lines were treated with $5 \mu \mathrm{M}$ DAC, the mRNA extracted and RT-PCR performed. Data presented in Figure 1 demonstrates that T98G and A172 cells did not express ACTL8, CTCFL and $X A G E 3$, yet after three days of exposure to DAC, these cell lines presented a remarkable expression of these antigens. Both cell lines expressed OIP5 and DAC treatment did not affect its expression. $\beta$-ACTIN (an endogenous control) was equally expressed in all cell lines before and after DAC treatment

\section{Prognostic value of CTA expression in GBM patients}

Significant associations between clinical characteristics of GBM patients (age, KPS, extent of resection, radiotherapy and chemotherapy) and expression of ACTL8, CTCFL, OIP5 and XAGE3, as well as, coexpression of 3-4 CTAs, were evaluated. Nevertheless, no significant correlation was observed between the expression of these CTA genes and any of the clinical parameters analyzed (Supplementary Table S3).

Additionally, we investigated the correlation of the mRNA expression of the four selected CTA genes, individually or as a number of coexpressed genes, with overall survival. The OIP5-positive patients had a longer survival period than the OIP5-negative group (48 weeks versus 23 weeks) and this difference was statistically significant $(\mathrm{P}=0.032$, hazards ratio $=0.53$, 95\% CI =0.28-1.0; Figure 4). Further, patients whose tumors coexpressed 3-4 CTA genes also showed better overall survival (100 weeks 3-4 CTA versus 26 weeks 0-2 $\mathrm{CTA}, \mathrm{P}=0.017$, hazards ratio $=0.36,95 \% \mathrm{CI}=0.17-0.74$; Figure 4). RT-PCR positivity for ACTL8, CTCFL and $X A G E 3$ was not associated with survival outcome in this cohort. It is noteworthy that an association between age and survival was also found as expected in a GBM population (data not shown).

To detect independent predictors of survival, an analysis of prognostic variables based on the Cox proportional hazards model was performed involving significant clinical features (age, KPS, extent of resection, radiotherapy and chemotherapy) and molecular variables (OIP5 expression and coexpression of 3-4 CTA genes) associated with survival probability. This multivariate survival analysis revealed that coexpression of 3-4 CTA genes $(\mathrm{P}=0.044$, hazards ratio $=0.3$, $95 \% \mathrm{CI}=0.093-0.963)$, radiotherapy $(\mathrm{P}=0.010$, hazards ratio $=0.16,95 \% \mathrm{CI}=0.04-0.65)$ and chemotherapy

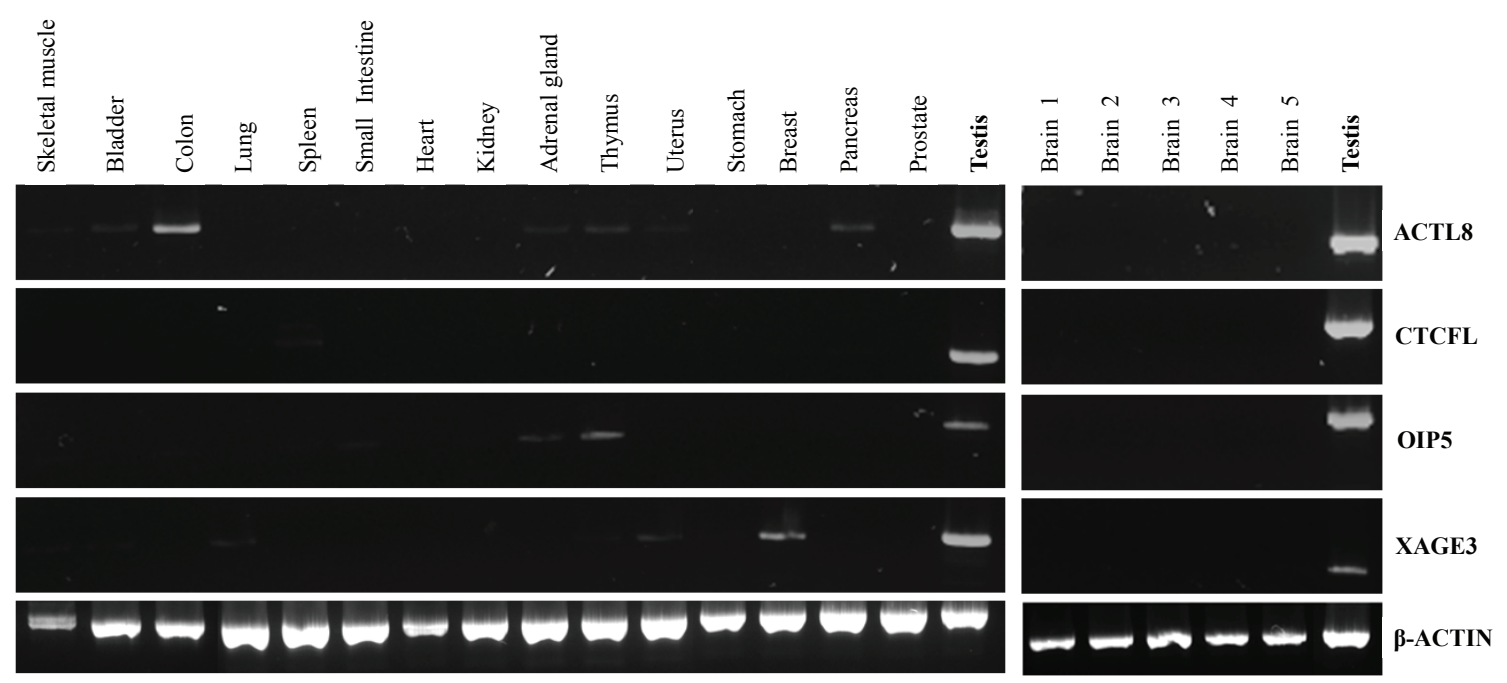

Figure 2: RT-PCR analysis of $A C T L 8, C T C F L, O I P 5$ and $X A G E 3$ expression in normal tissues. A commercially available panel of normal adult tissues (Clontech) was evaluated (left panel). The normal brain samples (right panel) were collected from patients with mesial temporal sclerosis during temporal lobectomy. An equal amount of testis cDNA was used as a representative positive control. 
$(\mathrm{P}=0.001$, hazards ratio $=0.10,95 \% \mathrm{CI}=0.03-0.41)$ remained as independent predictors of overall survival (Table 2).

\section{DISCUSSION}

Glioblastoma is one of the most lethal human cancers, with very few long-term survivors (1). Despite aggressive multimodal therapy, including surgery, radiation and chemotherapy, the prognosis for patients with this high-grade astrocytoma remains poor. Thus, glioblastoma is a relevant clinical problem, while successful strategies for its treatment have remained elusive.

Cancer vaccines are a promising cancer treatment due to low toxicity, the potential for circumventing drug cross-resistance and the potential for persistence of the antitumor effect caused by immunologic memory (17). There is a growing interest in applying tumor immunotherapy approaches to primary brain tumors, boosted by the recent FDA approvals of Sipuleucel-T for prostate cancer and Ipilimumab for metastatic melanoma $(18,19)$. In order to search for new tumorassociated antigens capable of inducing a tumor-directed immune response and to contribute to the development of immunotherapy approaches for glioblastomas, the present study evaluated a broad panel of CTA genes in a large number of GBM samples.
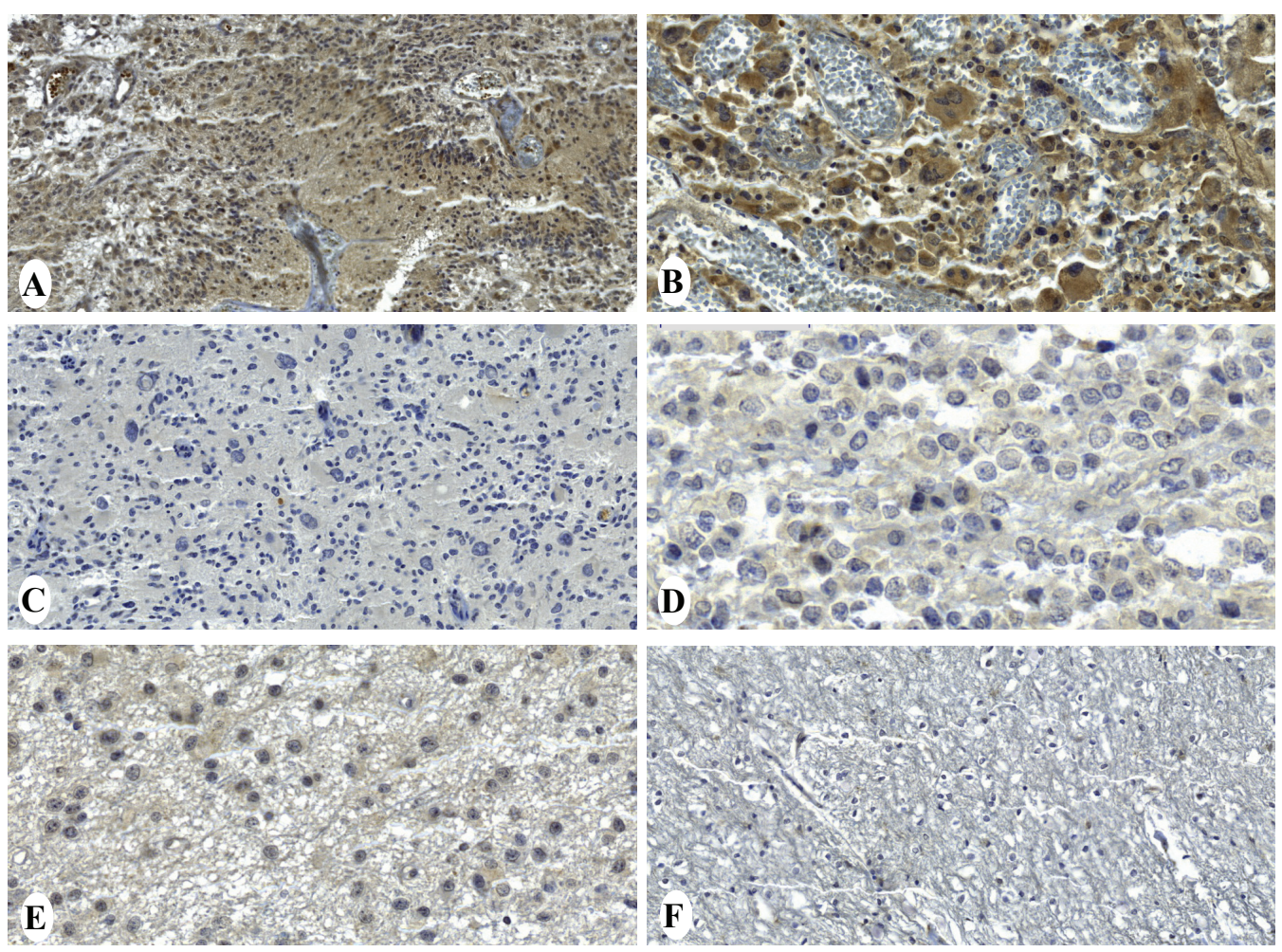

Figure 3: Immunohistochemical staining of $\boldsymbol{C T C F L}$ protein in gliomas and normal brain tissue. GBM samples showing diffuse cytoplasmic staining (A, B) and negative expression (C). Anaplastic astrocytoma (D), diffuse astrocytoma (E) and normal brain tissue (F). Magnification: $50 \mu \mathrm{m}(\mathrm{B}, \mathrm{D}, \mathrm{F})$ and $100 \mu \mathrm{m}(\mathrm{A}, \mathrm{C}, \mathrm{E})$. 
these four CTA genes showed no expression in normal brain tissues, but their expression is not restricted to testis and could be detected in few other normal tissues (testis-selective). Among the 15 normal adult tissues tested in our study, CTCFL was found expressed only in spleen, while a very low expression of $X A G E 3, O I P 5$ and $A C T L 8$ could be detected in other distinct normal adult tissues. According to Caballero and Chen (4), many CTA genes showed low-level mRNA expression in a limited number of somatic tissues; however, this low-level CTA expression has never been confirmed at the protein level by immunohistochemical analysis with anti-CTA antibodies, and whether such basal RNA expression translates to a biologically significant $(6,22)$.

The present study confirms that a large proportion of glioblastomas present CTA expression, suggesting that $A C T L 8, C T C F L, O I P 5$ and XAGE3 may be eligible for future vaccines clinical trials targeting multiple antigens; however, the demonstration of immunogenicity in the human host is crucial for these CTA be considered as a potential cancer vaccine target. Of note, a multi-epitopepulsed dendritic cell vaccine (including synthetic class I peptides from MAGE1) for patients with newly diagnosed glioblastoma was recently tested in a phase I trial (9).

The biological function of CTA genes remains poorly understood. CTCFL, also known as BORIS, is a transcriptional regulator; it directs epigenetic reprogramming at CTCF target sites in normal and tumor tissues $(23,24)$. Furthermore, it has been proposed as a mediator of the induction/derepression of other CTA genes $(8,24)$. OIP5 seems to be involved in chromatin reorganization during the cell cycle (25). Previous studies have demonstrated high expression of OIP5 mRNA in gastric, colorectal, lung and esophageal carcinomas, where it contributes to the growth of cancer cells $(25,26)$.
Table 2: Multivariate analysis of overall survival (Cox regression model).

\begin{tabular}{|l|l|l|l|}
\hline Variables & $\begin{array}{l}\text { Hazards } \\
\text { ratio }\end{array}$ & $\mathbf{9 5 \%}$ CI & $\mathbf{p}$ \\
\hline Radiotherapy & 0.16 & $0.04-0.65$ & 0.010 \\
\hline Chemotherapy & 0.10 & $0.03-0.41$ & 0.001 \\
\hline $\begin{array}{l}\text { 3-4 CTA genes } \\
\text { positivity }\end{array}$ & 0.30 & $0.093-0.963$ & 0.044 \\
\hline
\end{tabular}

No information about biological function of ACTL 8 and $X A G E 3$ is available.

Interestingly, some studies have failed to observe a clear correlation between mRNA level and protein expression of tumor antigens $(11,27)$. Although we have analyzed different patient cohorts by RT-PCR and immunohistochemical staining, our data correspond to similar expression frequencies at mRNA and protein levels of CTCFL ( $15 \%$ and $13 \%$, respectively). Also noteworthy, immunohistochemical staining revealed that CTCFL expression was frequently detected in GBM specimens but was completely negative in all less aggressive astrocytomas (Grade I, II or III) cases. This finding is consistent with the previous observation that CTA antigens are more often expressed in tumors of higher histological grade and later clinical stage (28, 29). For instance, MAGE-A1 expression has been found in $48 \%$ of metastatic melanoma versus $16 \%$ of primary melanoma (30) and NY-ESO-1 has been found to be expressed in $40 \%$ of grade 3 bladder tumors and $23 \%$ of grade 2 tumors, but in none of the grade 1 tumors (31).

As mentioned above, CTA are suitable targets for immunotherapy of human malignancies, and different clinical trials are ongoing. Nevertheless, the heterogeneous intratumor expression of CTA may hamper
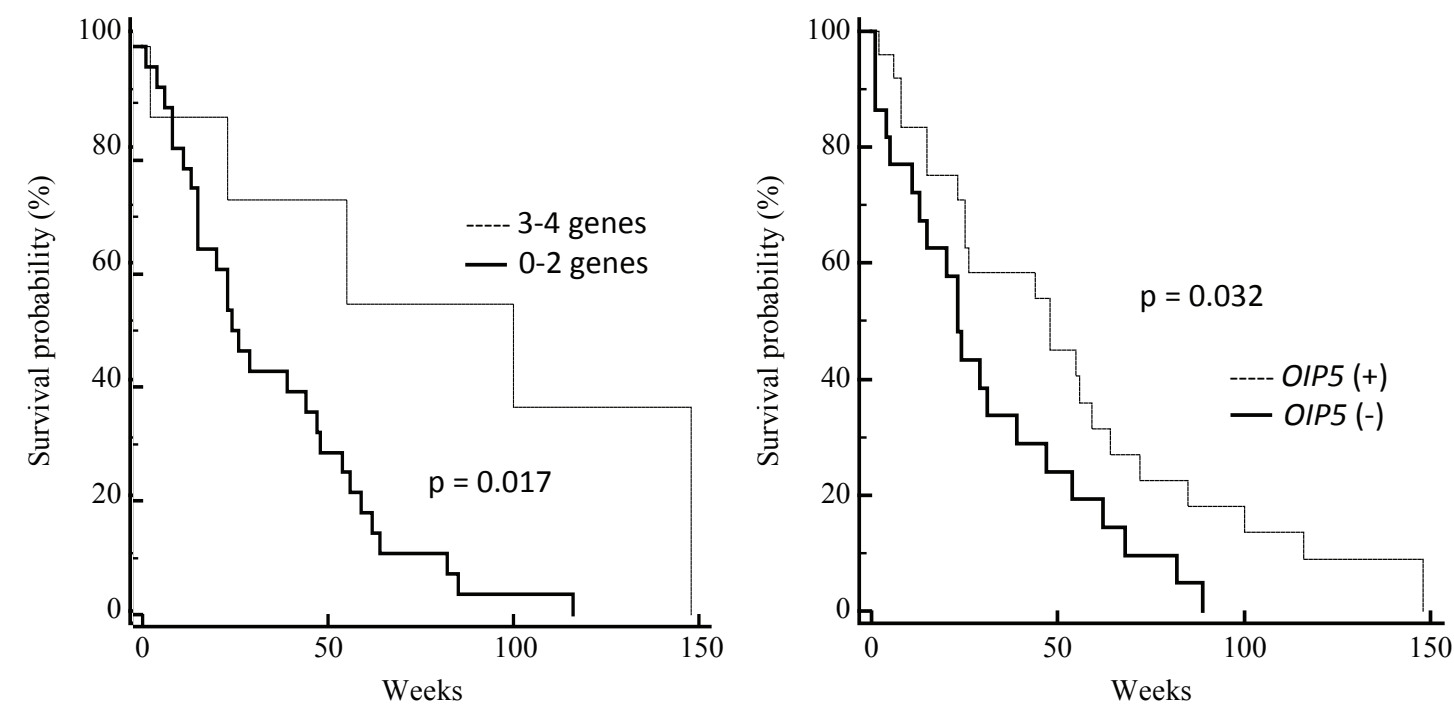

Figure 4: Correlation between CTA gene expression and overall survival of GBM patients. Kaplan-Meier survival estimates of patients were performed according to RT-PCR positivity of OIP5 and coexpression of multiple CTA (0-2 versus 3-4). 
the effectiveness of CTA-directed vaccination through the emergence of CTA-negative neoplastic clones. Therefore, it would be important to induce antigen expression in CTA-negative tumors prior to immunization (32). Methylation of $\mathrm{CpG}$ islands in CTA gene promoters is the primary silencing mechanism in healthy somatic tissues. Activation of CTA gene expression in tumors is thought to result from demethylation of these sequences (33). Our results demonstrated that DAC treatment should induce a reduction in DNA methylation and, consequently, increases the expression of CTA genes in GBM cells. Different studies have shown that DAC can upregulate the expression of CTA antigens on tumor cells, while it has been observed that DAC cannot induce CTA expression in cell lines derived from normal tissues as fibroblasts, endothelial cells, myoblasts, keratinocytes, and melanocytes (33-35). Although it is possible that $\mathrm{CpG}$ islands in the promoter regions are so densely methylated in normal cells as to render DAC ineffective, the possibility that other mechanisms of transcriptional, and even post-transcriptional, control of gene expression might be at play is highly likely. Taken together, these results suggest a potential utility of combining DAC therapy with CTA immunotherapy approaches as an alternative treatment option for GBM patients.

The identification of human tumor antigens could be important for the identification of molecular markers useful for diagnosis or prognosis (36). Clinical predictors of prognosis for patients with GBM include patient age and performance status, while molecular markers that effectively predict response to therapy and survival outcomes are limited (37). Currently, promoter methylation of the DNA repair gene O6-methylguanine methyltransferase (MGMT) is recognized as a reliable indicator of favorable response to radiotherapy and chemotherapy (38). In light of these considerations, our study identified a significant association between coexpression of 3-4 CTA genes and overall survival in patients with GBM, suggesting its use as potential a new prognostic indicator.

Most of previous studies have reported an association of CTA expression with poor outcome in multiple myeloma, ovarian cancer, lung cancer, head and neck cancer and gastric cancer (39-43). On the other hand, Sharma et al. described a positive association between expression of CT10 and improved survival for patients with urothelial carcinoma (44). Additional prospective studies with independent cohorts of GBM patients are needed to confirm the positive correlation between CTA expression and better disease outcome, but, based in our results, we can speculate that the presence of these CTA in glioblastoma tissues may have elicited a spontaneous immune response and this could impact favorably the prognosis.

In conclusion, the present study, one of the largest evaluating CTA expression in GBM reported to date, found that ACTL8, CTCFL, OIP5 and XAGE3 expression was characteristic of the majority of GBM examined. The coexpression of 3-4 of these CTA showed a significant association with increased overall survival, suggesting their use as a new prognostic marker and as potential targets for immunotherapy approaches in GBM treatment.

\section{MATERIAL AND METHODS}

\section{Patients and tissue samples}

A total of 48 tumor samples were obtained from GBM lesions excised from patients operated at São Paulo Hospital/ Federal University of São Paulo between 2002 and 2010. The glioma diagnoses were confirmed by a neuropathologist and all cases were classified morphologically according to the World Health Organization (WHO) classification. None of the patients had received prior cytotoxic or radiation therapy. All samples were checked microscopically for the presence of neoplastic tissue and the absence of contaminating normal brain tissue. Four normal brain specimens were collected from patients with mesial temporal sclerosis during temporal lobectomy at Sao Paulo Hospital (Sao Paulo, SP, Brazil). All tissue samples were snap-frozen in liquid nitrogen within 30 minutes of resection and stored at $-80^{\circ} \mathrm{C}$ until RNA extraction. One normal brain RNA sample acquired from Clontech was also analyzed in the study.

Paraffin-embedded tissue samples from 92 glioblastomas, 15 anaplastic astrocytomas, 48 diffuse astrocytomas, 38 pilocytic astrocytomas and 40 normal brain samples were obtained from the files of the Department of Pathology of A. C. Camargo Hospital (Sao Paulo, SP, Brazil) and used to construct a tissue microarray.

Tissue sampling and study design were approved by the Research Ethics Committee of the Federal University of São Paulo. Informed consent was obtained from all patients or from their legal guardians. Clinical information was collected from patients' medical records.

\section{RNA isolation and RT-PCR assays}

Forty-eight GBM specimens were available for RNA extraction. Total RNA was isolated using the RNeasy Mini Kit (Qiagen), following the manufacturer's instructions. Potentially contaminating DNA was removed by treating with RNase-free DNase (Qiagen). The resulting RNA concentration was measured spectrophotometrically (NanoDrop 1000 Spectrophotometer, Thermo Fischer Scientific) and the quality of the RNAs was checked by electrophoresis on $1 \%$ agarose gel. 
CTA expression was determined by the reverse transcription- polymerase chain reaction (RT-PCR). One microgram of each RNA sample was subjected to cDNA synthesis using the SuperScript III First-Strand Synthesis System (Invitrogen). The cDNA obtained was diluted 10X before use.

RT-PCR analysis was limited by the availability of specimens: OIP5 and XAGE3 were assessed in all 48 samples, CTCFL in 46 cases, and ACTL 8 in 37 cases. The mRNA expression of the selected CTA was determined by using previously published oligonucleotide primers (Supplementary Table S1). All PCR reactions were performed as described in the CTDatabase (http://www. cta.lncc.br) (7). Briefly, after an initial denaturation step for 3 minutes at $95^{\circ} \mathrm{C}$, the samples were subjected to 35 cycles of denaturation at $95^{\circ} \mathrm{C}$ for 15 seconds, annealing of 30 seconds $\left(10\right.$ cycles at $60^{\circ} \mathrm{C}, 10$ cycles at $58^{\circ} \mathrm{C}$ and 15 cycles at $56^{\circ} \mathrm{C}$ ) and extension of 30 seconds at $72^{\circ} \mathrm{C}$, followed by a final extension of 7 minutes at $72^{\circ} \mathrm{C}$. The $12.5 \mu \mathrm{l}$ reaction mixtures contained $1.25 \mu \mathrm{L} 10 \mathrm{x}$ PCR buffer, $0.25 \mu \mathrm{L} \mathrm{MgCl}_{2}(50 \mathrm{mM}), 0.125 \mu \mathrm{L}$ dNTPs $(10 \mathrm{mM})$, $0.25 \mu \mathrm{L}$ of each primer $(10 \mathrm{mM}), 0.125 \mu \mathrm{L}$ of Platinum Taq DNA Polymerase $(5 \mathrm{U} / \mu \mathrm{L})$ (Invitrogen) and $1 \mu \mathrm{L}$ of cDNA.

Testicular tissue was used as a positive control and the $\beta$-ACTIN was used as an internal quantity control. Electrophoresis was done by loading $12 \mu \mathrm{L}$ of each sample on $2 \%$ agarose gel and visualized by SYBR Safe staining using the EP AlphaImager (Alpha Innotech). Each RTPCR experiment was done in duplicate using the same cDNA sample. All cases with a detectable band on both replicates were considered positive. The intensities of the PCR products were heterogeneous, and some specimens yielded only faint bands. These were scored positive only if the result was reproducible by a repeated RT-PCR. Cases with very low transcript levels that were not reproducibly positive were regarded as negative.

\section{Selection of CTA genes}

We devised a strategy to select, from all 153 CTA genes described by Hofmann et al. (5), those genes potentially expressed in GBM and absent in normal brain. First, looking for CTA expressed in GBM, publicly available data on CTA expression in GBM held on the Oncomine (http://www.oncomine.org), NExtBio (http:// www.nextbio.com) and SAGE Anatomic Viewer (http:// cgap.nci.nih.gov/SAGE/AnatomicViewer) databases was mined. Second, the high-throughput expression data (EST, MPSS, CAGE) provided by Hofmann et al (5), the published data of CTA mRNA expression in cell lines (CTDatabase, http://www.cta.lncc.br/index.php), as well as, the data available in the literature, was evaluated. This allowed selection of the most promising CTA genes for subsequent evaluation of their expression in the GBM samples."

\section{Tissue Microarray}

For tissue microarray (TMA) construction, haematoxylin / eosin sections were analyzed and representative areas of tumors marked on the slides. Tissues corresponding to selected areas were taken from the donor block, using a tissue microarrayer (Beecher Instruments). Each sample was arrayed once with a 0.6$\mathrm{mm}$ diameter core spaced $0.2-\mathrm{mm}$ apart. The sampling consisted of four malignant cores from different areas of the tumor, placed coordinately in the array. Separate samples of normal brain were used as controls. After completion of the array, slides containing serial sections of $4 \mu \mathrm{m}$ of the TMA block were prepared. Two sections, $40 \mu \mathrm{m}$ distal from each other, were used for the immunohistochemical study.

\section{Immunohistochemistry}

The expression of CTCFL protein was investigated in astrocytoma samples arranged in a TMA. Rabbit polyclonal antibody against CTCFL protein (1:100 dilution; HPA001472, Sigma) was used as the primary antibody. Four- $\mu \mathrm{m}$ serial sections of the specimens were rehydrated and incubated in 3\% aqueous hydrogen peroxide for $30 \mathrm{~min}$ to quench endogenous peroxidase activity. Incubation with $1 \%$ bovine serum albumin and $5 \%$ fetal calf serum in Tris- $\mathrm{HCl} \mathrm{pH} 7.4$ was performed for $60 \mathrm{~min}$ at room temperature to suppress non-specific binding of subsequent reagents. The sections were then submitted to antigen retrieval with citrate $\mathrm{pH} 6.0$, followed by incubation with primary antibodies. A standard peroxidase-conjugated streptavidin-biotin method was used to detect the staining reaction (LSAB+; DAKO). External positive control tissues included placenta and normal testis samples. A semi-quantitative scoring method was used to evaluate immunohistochemical staining: negative reaction $(-):<10 \%$ positively stained cells; weakly positive reaction $(+): 10 \%$ to $25 \%$ of cells show positive reaction; moderately positive reaction $(++): 25 \%$ to $50 \%$ of tumor cells with positive reaction; strongly positive reaction $(+++)$ : more than $50 \%$ of tumor cells with positive reaction. Results of immunohistochemical data were grouped into negative and positive. Tumors with negative and weakly positive immunohistochemical reaction were considered negative, while tumors with moderately positive and strongly positive immunohistochemical reaction were considered positive.

\section{Cell lines treatment with 5-Aza-dC}

A172 and T98G human GBM cell lines were grown in DMEM (Invitrogen) supplemented with 10\% 
fetal bovine serum and $40 \mu \mathrm{L} / \mathrm{mL}$ garamycin. Cells were maintained at $37^{\circ} \mathrm{C}$ in a humid atmosphere containing $5 \%$ $\mathrm{CO}_{2}$. Cells were counted and plated in 75-cm dishes 1 day prior to treatment, and then the media was removed and replaced with fresh media containing $5 \mu \mathrm{M}$ of 5 -aza-2'deoxycytidine (decitabine, DAC; Sigma) for 3 consecutive days.

\section{Statistical Analysis}

Statistical analysis was performed using MedCalc (ver. 12.3.0). The Chi-square test and Fisher's exact test were used to evaluate the associations between CTA expression and clinical variables, as appropriate. The Kaplan-Meier method was used to estimate overall survival of patients, and differences between groups were compared using the log-rank test. Overall survival (OS) was measured as the time from the date of the surgery for the primary tumor until the date of death from any cause. Multivariate analyses were performed using the Cox proportional hazard model to determine the independent contribution of significant clinical and molecular variables. A stepwise elimination procedure was used for model selection, with a $\mathrm{P}=0.2$ threshold for elimination. Results were calculated with $95 \%$ confidence intervals (CI). For all analyses, a $\mathrm{P}$ value was less than 0.05 was considered statistically significant.

\section{FUNDING}

This work was supported by Fundação de Amparo à Pesquisa do Estado de São Paulo - FAPESP grant (2010/20218/2). M.R.P.F. was recipient of scholarship from Coordenação de aperfeiçoamento de Pessoal de Nível Superios (CAPES) as student of PhD program at Disciplina de Hematologia e Hemoterapia, Universidade Federal de São Paulo. T.P.B. and F.T.Z were recipients of scholarships from the FAPESP. A. L. V. has a National Counsel of Technological and Scientific Development CNPq scholarship.

\section{Conflict of interest}

The authors have declared that no competing interests exist.

\section{ACKNOWLEDGMENT}

The authors would like to thanks Dr. Otávia L. Caballero for review the manuscript.

\section{REFERENCES}

1. Stupp R, Mason WP, van den Bent MJ, Weller M, Fisher
B, Taphoorn MJ, Belanger K, Brandes AA, Marosi C, Bogdahn U, Curschmann J, Janzer RC, Ludwin SK, Gorlia T, Allgeier A, Lacombe D, et al. Radiotherapy plus concomitant and adjuvant temozolomide for glioblastoma. The New England journal of medicine. 2005; 352(10):987996.

2. Grauer OM, Wesseling P and Adema GJ. Immunotherapy of diffuse gliomas: biological background, current status and future developments. Brain pathology. 2009; 19(4):674693.

3. Mitchell DA, Fecci PE and Sampson JH. Immunotherapy of malignant brain tumors. Immunological reviews. 2008; 222:70-100.

4. Caballero OL and Chen YT. Cancer/testis (CT) antigens: potential targets for immunotherapy. Cancer science. 2009; 100(11):2014-2021.

5. Hofmann O, Caballero OL, Stevenson BJ, Chen YT, Cohen T, Chua R, Maher CA, Panji S, Schaefer U, Kruger A, Lehvaslaiho M, Carninci P, Hayashizaki Y, Jongeneel CV, Simpson AJ, Old LJ, et al. Genome-wide analysis of cancer/testis gene expression. Proceedings of the National Academy of Sciences of the United States of America. 2008; 105(51):20422-20427.

6. Scanlan MJ, Simpson AJ and Old LJ. The cancer/testis genes: review, standardization, and commentary. Cancer immunity. 2004; 4:1.

7. CTDatabase.

8. Fratta E, Coral S, Covre A, Parisi G, Colizzi F, Danielli R, Nicolay HJ, Sigalotti L and Maio M. The biology of cancer testis antigens: putative function, regulation and therapeutic potential. Molecular oncology. 2011; 5(2):164-182.

9. Phuphanich S, Wheeler CJ, Rudnick JD, Mazer M, Wang H, Nuno MA, Richardson JE, Fan X, Ji J, Chu RM, Bender JG, Hawkins ES, Patil CG, Black KL and Yu JS. Phase I trial of a multi-epitope-pulsed dendritic cell vaccine for patients with newly diagnosed glioblastoma. Cancer immunology, immunotherapy : CII. 2012.

10. Scarcella DL, Chow CW, Gonzales MF, Economou C, Brasseur F and Ashley DM. Expression of MAGE and GAGE in high-grade brain tumors: a potential target for specific immunotherapy and diagnostic markers. Clinical cancer research : an official journal of the American Association for Cancer Research. 1999; 5(2):335-341.

11. Syed ON, Mandigo CE, Killory BD, Canoll P and Bruce JN. Cancer-testis and melanocyte-differentiation antigen expression in malignant glioma and meningioma. Journal of clinical neuroscience : official journal of the Neurosurgical Society of Australasia. 2012; 19(7):1016-1021.

12. Chi DD, Merchant RE, Rand R, Conrad AJ, Garrison D, Turner R, Morton DL and Hoon DS. Molecular detection of tumor-associated antigens shared by human cutaneous melanomas and gliomas. The American journal of pathology. 1997; 150(6):2143-2152.

13. Lee MH, Son EI, Kim E, Kim IS, Yim MB and Kim SP. 
Expression of cancer-testis genes in brain tumors. Journal of Korean Neurosurgical Society. 2008; 43(4):190-193.

14. Ueda R, Kinoshita E, Ito R, Kawase T, Kawakami Y and Toda M. Induction of protective and therapeutic antitumor immunity by a DNA vaccine with a glioma antigen, SOX6. International journal of cancer Journal international du cancer. 2008; 122(10):2274-2279.

15. Gao F, You T, Lu JY and Wang YJ. [Research on the expression of cancer associated gene in the intracranial tumors]. Sichuan da xue xue bao Yi xue ban = Journal of Sichuan University Medical science edition. 2006; 37(3):424-426.

16. Sahin U, Tureci O, Chen YT, Seitz G, Villena-Heinsen C, Old LJ and Pfreundschuh M. Expression of multiple cancer/ testis (CT) antigens in breast cancer and melanoma: basis for polyvalent $\mathrm{CT}$ vaccine strategies. International journal of cancer Journal international du cancer. 1998; 78(3):387389.

17. Emens LA and Jaffee EM. Cancer vaccines: an old idea comes of age. Cancer biology \& therapy. 2003; 2(4 Suppl 1):S161-168.

18. Cheever MA and Higano CS. PROVENGE (Sipuleucel-T) in prostate cancer: the first FDA-approved therapeutic cancer vaccine. Clinical cancer research : an official journal of the American Association for Cancer Research. 2011; 17(11):3520-3526.

19. Traynor K. Ipilimumab approved for metastatic melanoma. American journal of health-system pharmacy : AJHP : official journal of the American Society of Health-System Pharmacists. 2011; 68(9):768.

20. Sahin U, Koslowski M, Tureci O, Eberle T, Zwick C, Romeike B, Moringlane JR, Schwechheimer K, Feiden W and Pfreundschuh M. Expression of cancer testis genes in human brain tumors. Clinical cancer research : an official journal of the American Association for Cancer Research. 2000; 6(10):3916-3922.

21. Natsume A, Wakabayashi T, Tsujimura K, Shimato S, Ito M, Kuzushima K, Kondo Y, Sekido Y, Kawatsura H, Narita $\mathrm{Y}$ and Yoshida J. The DNA demethylating agent 5-aza-2'-deoxycytidine activates NY-ESO-1 antigenicity in orthotopic human glioma. International journal of cancer Journal international du cancer. 2008; 122(11):2542-2553.

22. Tureci O, Chen YT, Sahin U, Gure AO, Zwick C, Villena C, Tsang S, Seitz G, Old LJ and Pfreundschuh M. Expression of SSX genes in human tumors. International journal of cancer Journal international du cancer. 1998; 77(1):19-23.

23. Woloszynska-Read A, James SR, Link PA, Yu J, Odunsi $\mathrm{K}$ and Karpf AR. DNA methylation-dependent regulation of BORIS/CTCFL expression in ovarian cancer. Cancer immunity. 2007; 7:21.

24. Risinger JI, Chandramouli GV, Maxwell GL, Custer M, Pack S, Loukinov D, Aprelikova O, Litzi T, Schrump DS, Murphy SK, Berchuck A, Lobanenkov V and Barrett JC. Global expression analysis of cancer/testis genes in uterine cancers reveals a high incidence of BORIS expression. Clinical cancer research : an official journal of the American Association for Cancer Research. 2007; 13(6):1713-1719.

25. Koinuma J, Akiyama H, Fujita M, Hosokawa M, Tsuchiya E, Kondo S, Nakamura Y and Daigo Y. Characterization of an Opa interacting protein 5 involved in lung and esophageal carcinogenesis. Cancer science. 2012; 103(3):577-586.

26. Chun HK, Chung KS, Kim HC, Kang JE, Kang MA, Kim JT, Choi EH, Jung KE, Kim MH, Song EY, Kim SY, Won $\mathrm{M}$ and Lee HG. OIP5 is a highly expressed potential therapeutic target for colorectal and gastric cancers. BMB reports. 2010; 43(5):349-354.

27. Oba-Shinjo SM, Caballero OL, Jungbluth AA, Rosemberg S, Old LJ, Simpson AJ and Marie SK. Cancer-testis (CT) antigen expression in medulloblastoma. Cancer immunity. 2008; 8:7.

28. Chen YT, Ross DS, Chiu R, Zhou XK, Chen YY, Lee P, Hoda SA, Simpson AJ, Old LJ, Caballero O and Neville AM. Multiple cancer/testis antigens are preferentially expressed in hormone-receptor negative and high-grade breast cancers. PloS one. 2011; 6(3):e17876.

29. Chen YT, Chadburn A, Lee P, Hsu M, Ritter E, Chiu A, Gnjatic S, Pfreundschuh M, Knowles DM and Old LJ. Expression of cancer testis antigen CT45 in classical Hodgkin lymphoma and other B-cell lymphomas. Proceedings of the National Academy of Sciences of the United States of America. 2010; 107(7):3093-3098.

30. Brasseur F, Rimoldi D, Lienard D, Lethe B, Carrel S, Arienti F, Suter L, Vanwijck R, Bourlond A, Humblet $\mathrm{Y}$ and et al. Expression of MAGE genes in primary and metastatic cutaneous melanoma. International journal of cancer Journal international du cancer. 1995; 63(3):375380 .

31. Kurashige $\mathrm{T}$, Noguchi $\mathrm{Y}$, Saika T, Ono T, Nagata $\mathrm{Y}$, Jungbluth A, Ritter G, Chen YT, Stockert E, Tsushima T, Kumon H, Old LJ and Nakayama E. Ny-ESO-1 expression and immunogenicity associated with transitional cell carcinoma: correlation with tumor grade. Cancer research. 2001; 61(12):4671-4674.

32. Sigalotti L, Fratta E, Coral S, Tanzarella S, Danielli R, Colizzi F, Fonsatti E, Traversari C, Altomonte M and Maio M. Intratumor heterogeneity of cancer/testis antigens expression in human cutaneous melanoma is methylation-regulated and functionally reverted by 5 -aza2'-deoxycytidine. Cancer research. 2004; 64(24):91679171.

33. De Smet C, Loriot A and Boon T. Promoter-dependent mechanism leading to selective hypomethylation within the 5 ' region of gene MAGE-A1 in tumor cells. Molecular and cellular biology. 2004; 24(11):4781-4790.

34. Schrump DS, Fischette MR, Nguyen DM, Zhao M, Li X, Kunst TF, Hancox A, Hong JA, Chen GA, Pishchik V, Figg WD, Murgo AJ and Steinberg SM. Phase I study of decitabine-mediated gene expression in patients with 
cancers involving the lungs, esophagus, or pleura. Clinical cancer research : an official journal of the American Association for Cancer Research. 2006; 12(19):5777-5785.

35. Weber J, Salgaller M, Samid D, Johnson B, Herlyn M, Lassam N, Treisman J and Rosenberg SA. Expression of the MAGE-1 tumor antigen is up-regulated by the demethylating agent 5-aza-2'-deoxycytidine. Cancer research. 1994; 54(7):1766-1771.

36. Kawakami Y, Fujita T, Matsuzaki Y, Sakurai T, Tsukamoto M, Toda M and Sumimoto H. Identification of human tumor antigens and its implications for diagnosis and treatment of cancer. Cancer science. 2004; 95(10):784-791.

37. Ohgaki $\mathrm{H}$ and Kleihues P. Population-based studies on incidence, survival rates, and genetic alterations in astrocytic and oligodendroglial gliomas. Journal of neuropathology and experimental neurology. 2005; 64(6):479-489.

38. Hegi ME, Diserens AC, Gorlia T, Hamou MF, de Tribolet N, Weller M, Kros JM, Hainfellner JA, Mason W, Mariani L, Bromberg JE, Hau P, Mirimanoff RO, Cairncross JG, Janzer RC and Stupp R. MGMT gene silencing and benefit from temozolomide in glioblastoma. The New England journal of medicine. 2005; 352(10):997-1003.

39. Andrade VC, Vettore AL, Felix RS, Almeida MS, Carvalho F, Oliveira JS, Chauffaille ML, Andriolo A, Caballero OL, Zago MA and Colleoni GW. Prognostic impact of cancer/testis antigen expression in advanced stage multiple myeloma patients. Cancer immunity. 2008; 8:2.

40. Yakirevich E, Sabo E, Lavie O, Mazareb S, Spagnoli GC and Resnick MB. Expression of the MAGE-A4 and NYESO-1 cancer-testis antigens in serous ovarian neoplasms. Clinical cancer research : an official journal of the American Association for Cancer Research. 2003; 9(17):6453-6460.

41. Gure AO, Chua R, Williamson B, Gonen M, Ferrera CA, Gnjatic S, Ritter G, Simpson AJ, Chen YT, Old LJ and Altorki NK. Cancer-testis genes are coordinately expressed and are markers of poor outcome in non-small cell lung cancer. Clinical cancer research : an official journal of the American Association for Cancer Research. 2005; 11(22):8055-8062.

42. Cuffel C, Rivals JP, Zaugg Y, Salvi S, Seelentag W, Speiser DE, Lienard D, Monnier P, Romero P, Bron L and Rimoldi D. Pattern and clinical significance of cancer-testis gene expression in head and neck squamous cell carcinoma. International journal of cancer Journal international du cancer. 2011; 128(11):2625-2634.

43. Jung EJ, Kim MA, Lee HS, Yang HK, Lee YM, Lee BL and Kim WH. Expression of family A melanoma antigen in human gastric carcinoma. Anticancer research. 2005; 25(3B):2105-2111.

44. Sharma P, Shen Y, Wen S, Bajorin DF, Reuter VE, Old LJ and Jungbluth AA. Cancer-testis antigens: expression and correlation with survival in human urothelial carcinoma. Clinical cancer research : an official journal of the American Association for Cancer Research. 2006; 12(18):5442-5447. 